\title{
Evidence-based medicine: It's not a cookbook!
}

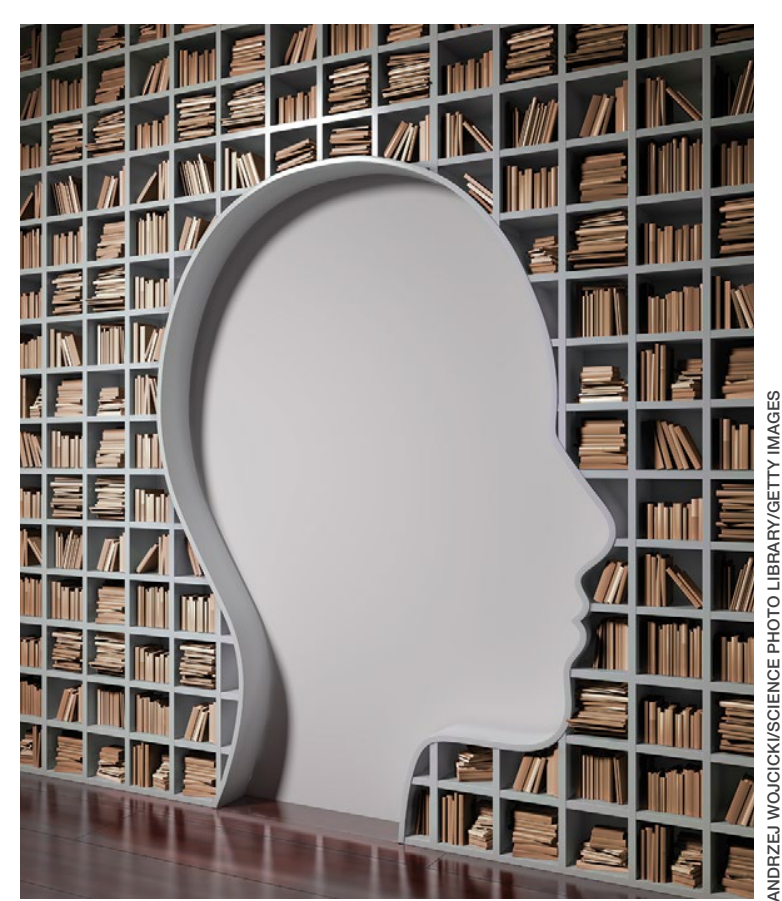

\section{Leslie Citrome, MD, MPH}

\section{Clinical Professor}

Department of Psychiatry \& Behavioral Sciences New York Medical College

Valhalla, New York

CurRent Psychiatry Section Editor, Psychopharmacology

\section{Dmitry Arbuck, MD}

Assistant Professor of Psychiatry and Medicine

Indiana University School of Medicine

Indianapolis, Indiana

President

Indiana Polyclinic

Carmel, Indiana

Current Psychiatry Associate Editor

\section{It's not just about the evidence, it's about how we use it in clinical practice}

$\mathrm{T}$ he term evidence-based medicine (EBM) has been derided by some as "cookbook medicine." To others, EBM conjures up the efforts of describing interventions in terms of comparative effectiveness, drowning us in a deluge of "evidence-based" publications. The moniker has also been hijacked by companies to name their Health Economics and Outcomes research divisions. The spirit behind EBM is getting lost. EBM is not just about the evidence; it is about how we use it. ${ }^{1}$

In this commentary, we describe the concept of EBM and discuss teaching EBM to medical students and residents, its role in continuing medical education, and how it may be applied to practice, using a case scenario as a guide.

\section{What is evidence-based medicine?}

Sackett et $\mathrm{al}^{2}$ summed it best in an editorial published in the BMJ in 1996, where he emphasized decision-making in the

\section{Disclosures}

No writing assistance or external financial support was utilized in the production of this article. In the past 12 months, Dr. Citrome has served as a consultant for AbbVie, Acadia, Alkermes, Allergan, Angelini, Astellas, Avanir, Axsome, BioXcel, Boehringer Ingelheim, Cadent Therapeutics, Eisai, Impel, Intra-Cellular Therapies, Janssen, Karuna, Lundbeck, Lyndra, Medavante-ProPhase, Merck, Neurocrine, Noven, Otsuka, Ovid, Relmada, Sage, Sunovion, Teva, and University of Arizona, and one-off ad hoc consulting for individuals/entities conducting marketing, commercial, or scientific scoping research. He has been a speaker for AbbVie, Acadia, Alkermes, Allergan, Angelini, Eisai, Intra-Cellular Therapies, Janssen, Lundbeck, Neurocrine, Noven, Otsuka, Sunovion, Takeda, Teva, and CME activities organized by medical education companies such as Medscape, NACCME, NEl, Vindico, and universities and professional organizations/societies. Dr. Citrome owns stocks (small number of shares of common stock): Bristol-Myers Squibb, Eli Lilly, Johnson \& Johnson, Merck, and Pfizer purchased $>10$ years ago. He has received royalties from Wiley (Editor-inChief, International Journal of Clinical Practice, through 2019), UpToDate (reviewer), Springer Healthcare (book), and Elsevier (Topic Editor, Psychiatry, Clinical Therapeutics). Dr. Arbuck reports no financial relationships with any companies whose products are mentioned in this article, or with manufacturers of competing products.

doi: 10.12788/cp.0124 


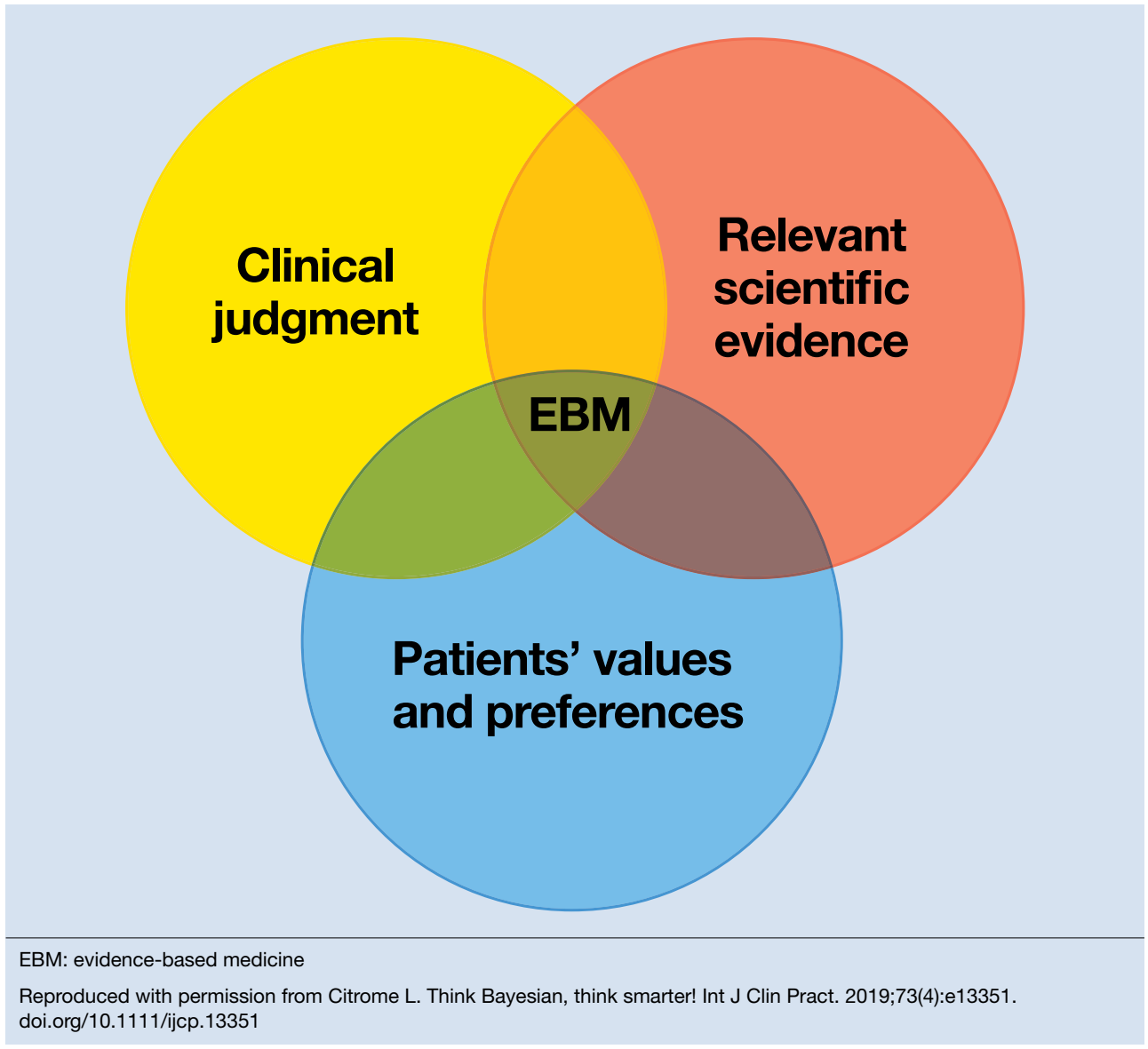

care of individual patients. When making clinical decisions, using the best evidence available makes sense, but so does integrating individual clinical expertise and considering the individual patient's preferences. Sackett et $\mathrm{al}^{2}$ warns about practice becoming tyrannized by evidence: “even excellent external evidence may be inapplicable to or inappropriate for an individual patient." Clearly, EBM is not cookbook medicine.

Figure $\mathbf{1}^{3}$ illustrates EBM as the confluence of clinical judgment, relevant scientific evidence, and patients' values and preferences. The results from a clinical trial are only one part of the equation. As practitioners, we have the advantage of detailed knowledge about the patient, and our decisions are not "one size fits all." Prior information about the patient dictates how we apply the evidence that supports potential interventions.
The concept of EBM was born out of necessity to bring scientific principles into the heart of medicine. As outlined by Sackett, ${ }^{4}$ the practice of EBM is a process of lifelong, self-directed learning in which caring for our own patients creates the need for clinically important information about diagnosis, prognosis, therapy, and other clinical and health care issues. Through EBM, we:

- convert these information needs into answerable questions

- track down, with maximum efficiency, the best evidence with which to answer questions (whether from clinical examination, diagnostic laboratory results, research evidence, or other sources)

- critically appraise that evidence for its validity (closeness to the truth) and usefulness (clinical applicability)

- integrate this appraisal with our clinical expertise and apply it in practice

- evaluate our performance.
Clinical Point

Prior information about the patient dictates how we apply the evidence that supports potential interventions

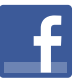

Discuss this article at www.facebook.com/ MDedgePsychiatry 


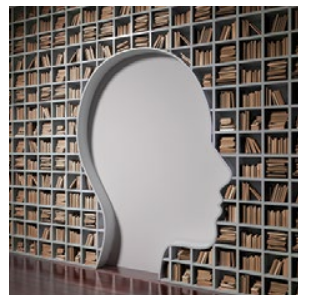

Evidence-based medicine

\section{Clinical Point}

The push to replace
clinical thinking
with general
dogmas trivializes
medical practice and
endangers treatment
outcomes

Over the years, the original aim of EBM as a self-directed method for clinicians to practice high-quality medicine was morphed by some into a tool of enforced standardization and a boilerplate approach to managing costs across systems of care. As a result, the term EBM has been criticized because of:

- its reliance on empiricism

- a narrow definition of evidence

- a lack of evidence of efficacy

- its limited usefulness for individual patients

- threats to the autonomy of the doctorpatient relationship.

These 5 categories are associated with severe drawbacks when used for individual patient care. ${ }^{5}$ In addition to problems with applying standardized population research to a specific patient with a specific set of symptoms, medications, genetic variations, and unique environment, it can take years for clinicians to change their practices to incorporate new information. ${ }^{6}$

Evidence that is too narrow in scope may not be useful. Single-molecule pharmaceutical clinical trials have erroneously become a synonym of EBM. Such studies do not reflect complex, real-life situations. Based on such studies, FDA product labeling can be inadequate in its guidance, particularly when faced with complex comorbidities. The standard comparison of active treatment to placebo is also seen as EBM, narrowing its scope and deflecting from clinical medicine when physicians measure one treatment's success against another vs measuring real treatments against shams. Reallife treatment choice is frequently based on considering adverse effects as important to consider as therapeutic efficacy; however, this concept is outside of the common (mis)understanding of EBM.

Conflicting and ever-changing data and the push to replace clinical thinking with general dogmas trivializes medical practice and endangers treatment outcomes. This would not happen to the extent we see now if EBM was again seen as a guide and general direction rather than a blanket, distorted requirement to follow rigid recommendations for specific patients.

Insurance companies have driven a change in the understanding of EBM by using the FDA label as an excuse to deny, delay, and/or refuse to pay for treatments that are not explicitly and narrowly onlabel. Dependence on on-label treatments is even more challenging in specialty medicine because primary care clinicians generally have tried the conventional approaches

\section{Figure 2}

\section{The 5-step evidence-based medicine process}

\begin{tabular}{|c|c|c|c|c|}
\hline Step 1 & Step 2 & Step 3 & Step 4 & Step 5 \\
\hline Formulate the question & Search for answers & Appraise the evidence & Apply the results & Assess the outcome \\
\hline $\begin{array}{l}\text { What kind of patient or } \\
\text { problem? } \\
\text { What intervention, } \\
\text { treatment, diagnostic } \\
\text { test, risk factor, or } \\
\text { prognostic factor are } \\
\text { you interested in? } \\
\text { What comparisons are } \\
\text { you making (treatment } \\
\text { A vs treatment B, } \\
\text { treatment vs no } \\
\text { treatment, etc.)? }\end{array}$ & $\begin{array}{l}\text { Does it work? } \\
\text { Has a systematic } \\
\text { review been conducted } \\
\text { (search Medline or the } \\
\text { Cochrane Database)? } \\
\text { Are there RCTs that } \\
\text { enrolled similar patients } \\
\text { to yours? } \\
\text { If using guidelines, are } \\
\text { they evidence-based } \\
\text { or eminence-based? } \\
\text { Well-formulated } \\
\text { questions make it } \\
\text { easier to locate an } \\
\text { answer, if one exists. }\end{array}$ & $\begin{array}{l}\text { Will it work in the "real } \\
\text { world"? } \\
\text { Is it relevant to your } \\
\text { question and your } \\
\text { patient? } \\
\text { Is the statistically } \\
\text { significant result } \\
\text { clinically significant? } \\
\text { If effect size is not } \\
\text { mentioned in the } \\
\text { research report, } \\
\text { is there sufficient } \\
\text { information available } \\
\text { to calculate the NNT } \\
\text { for the categorical } \\
\text { outcomes of interest? }\end{array}$ & $\begin{array}{l}\text { Is it worth it? } \\
\text { Is the intervention, } \\
\text { treatment, diagnostic } \\
\text { test, etc., important } \\
\text { to you within the } \\
\text { context of your } \\
\text { clinical experience } \\
\text { and important to the } \\
\text { patient in terms of } \\
\text { their preferences? }\end{array}$ & $\begin{array}{l}\text { Did you ask the right } \\
\text { question? } \\
\text { Did you find answers? } \\
\text { Were the answers } \\
\text { you found based on } \\
\text { a high-quality level of } \\
\text { evidence? } \\
\text { Did it make clinical } \\
\text { sense? } \\
\text { Did it make a } \\
\text { difference? } \\
\text { Can you quantify this? } \\
\text { Does the patient agree? } \\
\end{array}$ \\
\hline
\end{tabular}

NNT: number needed to treat; RCTs: randomized clinical trials

Reproduced with permission from Citrome L, Ketter TA. Teaching the philosophy and tools of evidence-based medicine: misunderstandings and solutions. Int J Clin Pract. 2009;63(3):353-359. 


\section{Is it evidence-based? Consider the scenario of Ms. A, age 20, who presents with a major depressive episode}

\begin{tabular}{|c|c|c|}
\hline $\begin{array}{l}\text { Assessment/ } \\
\text { intervention }\end{array}$ & $\begin{array}{l}\text { Is this evidence- } \\
\text { based? }\end{array}$ & Why or why not? \\
\hline $\begin{array}{l}\text { Ms. A is depressed, so } \\
\text { prescribe an SSRI }\end{array}$ & No & $\begin{array}{l}\text { The MDE may be because of bipolar disorder and not } \\
\text { major depressive disorder. Additional information is } \\
\text { needed to make an accurate diagnosis; otherwise, an } \\
\text { incorrect treatment may be provided, and that treatment } \\
\text { may worsen the underlying condition. There is no } \\
\text { information about individual circumstances that would } \\
\text { make treatment with an SSRI an EBM approach }\end{array}$ \\
\hline $\begin{array}{l}\text { Three years ago, } \\
\text { Ms. A had a hypomanic } \\
\text { episode that } \\
\text { spontaneously resolved. } \\
\text { Two years ago, she } \\
\text { had an MDE that was } \\
\text { treated successfully } \\
\text { with an SSRI without } \\
\text { any emergence of } \\
\text { hypomania, so prescribe } \\
\text { an SSRI }\end{array}$ & Yes & $\begin{array}{l}\text { More information is available. Diagnosis is } \\
\text { likely bipolar II, but Ms. A did do well with SSRI } \\
\text { monotherapy in the past. Although this appears to } \\
\text { be a non-EBM choice, individual patient values and } \\
\text { preferences, together with clinical judgment, make } \\
\text { this treatment consistent with EBM as originally } \\
\text { conceptualized. If it emerges that Ms. A has had } \\
\text { a manic episode, SSRI monotherapy would be a } \\
\text { suboptimal choice and the available evidence should } \\
\text { steer the clinician to avoid SSRI monotherapy }\end{array}$ \\
\hline $\begin{array}{l}\text { Three years ago, } \\
\text { Ms. A had a manic } \\
\text { episode that } \\
\text { resolved with lithium } \\
\text { combined with a } \\
\text { second-generation } \\
\text { antipsychotic, so } \\
\text { prescribe lamotrigine }\end{array}$ & No & $\begin{array}{l}\text { Available evidence tells us that lamotrigine is a } \\
\text { weak choice for an acute MDE and was never } \\
\text { approved for that purpose. Unless there are overriding } \\
\text { issues that would prevent the use of approved agents } \\
\text { for MDE associated with bipolar disorder, or if } \\
\text { Ms. A had received lamotrigine before and it helped } \\
\text { her, prescribing lamotrigine would not be consistent } \\
\text { with EBM }\end{array}$ \\
\hline $\begin{array}{l}\text { Three years ago, } \\
\text { Ms. A had a manic } \\
\text { episode that } \\
\text { resolved with lithium } \\
\text { combined with a } \\
\text { second-generation } \\
\text { antipsychotic, so } \\
\text { prescribe olanzapine- } \\
\text { fluoxetine combination, } \\
\text { quetiapine, lurasidone, } \\
\text { or cariprazine }\end{array}$ & Yes & $\begin{array}{l}\text { All } 4 \text { of these suggested choices are FDA-approved } \\
\text { for the treatment of MDE associated with bipolar } \\
\text { I disorder. Choosing among them will require } \\
\text { determining Ms. A's values and preferences (including } \\
\text { past history of response/nonresponse and sensitivity } \\
\text { to specific adverse events) and your clinical judgment } \\
\text { and experience (priority for efficacy needs, safety } \\
\text { considerations). Going outside these choices may } \\
\text { still be consistent with EBM, but there needs to be } \\
\text { actual evidence supporting the use of that intervention } \\
\text { (preferably a high-quality RCT) or evidence that it } \\
\text { worked for Ms. A in the past (the "N=1 trial") }\end{array}$ \\
\hline
\end{tabular}

before referring patients to a specialist. However, insurance denials rarely differentiate between practice settings.

Medicolegal issues have cemented the present situation when clinically valid "offlabel" treatments may be a reasonable consideration for patients but can place health care practitioners in jeopardy. The distorted EBM doctrine has become a justification for legal actions against clinicians who practice individualized medicine.

Concision bias (selectively focusing on information, losing nuance) and selection bias (patients in clinical trials who do not reflect real-life patients) have become an impediment to progress and EBM as originally intended.

\section{Training medical students and residents}

Although there is some variation in how EBM is taught to medical students and residents, ${ }^{7,8}$ the expectation is that such education occurs. The Accreditation Council for Graduate Medical Education requirements for a residency program state that "the program must advance residents'

\section{Clinical Point}

The distorted EBM doctrine has become a justification for legal actions against clinicians who practice individualized medicine 


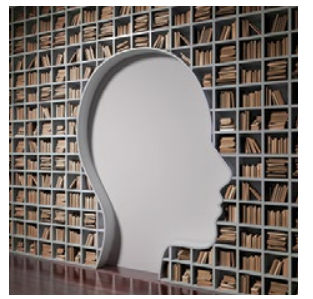

Evidence-based medicine

\section{Clinical Point}

Concision bias and selection bias have become an impediment to progress and EBM as originally intended

\section{Related Resources}

- Gray GE. Concise guide to evidence-based psychiatry. American Psychiatric Publishing, Inc.; 2003.

- Straus SE, Glasziou P, Richardson WS, et al. Evidence-based medicine: how to practice and teach EBM. 5th edition. Elsevier; 2018

- Guyatt G, Rennie D, Meade MO, et al. Users' guides to the medical literature: a manual for evidence-based clinical practice. 3rd edition. McGraw-Hill; 2014.

Drug Brand Names

Cariprazine • Vraylar

Lamotrigine - Lamictal

Lithium • Eskalith, Lithobid

Lurasidone • Latuda

knowledge and practice of the scholarly approach to evidence-based patient care." The topic has been part of the American Society of Clinical Psychopharmacology Model Psychopharmacology Curriculum, but only in an optional lecture. ${ }^{10}$ The formal teaching of EBM includes how to find relevant biomedical publications for the clinical issues at hand, understand the different hierarchies of evidence, interpret results in terms of effect size, and apply this knowledge in the care of patients. This 5 -step process is illustrated in Figure $2^{8}$ (page 36). See Related Resources for 3 books that provide a scholarly yet clinically relevant approach to EBM.

\section{Continuing medical education}

Most Current Psychiatry readers have been out of residency for some time and have not necessarily been exposed to the philosophy and tools of EBM. It may be easier to simply jump in and learn about effect sizes and then use information already curated and apply this knowledge. A good starting point is a recap ${ }^{11,12}$ of the Clinical Antipsychotic Trials of Intervention
Effectiveness (CATIE) for schizophrenia that answers the questions: "How large is the effect being measured?" "Is it clinically important?" and "How are we dealing with a result that may be statistically significant but irrelevant for day-to-day patient care?" Number needed to treat (NNT) and number needed to harm (NNH) can help explain this by allowing one to judge the clinical significance of a statistically significant result. ${ }^{13}$

\section{Practical applications}

There are common clinical scenarios where evidence is ignored, or where it is overvalued. For example, the treatment of bipolar depression can be made worse with the use of antidepressants. ${ }^{14}$ Does this mean that antidepressants should never be used? What about patient history and preference? What if the approved agents fail to relieve symptoms or are not well tolerated? Available FDAapproved choices may not always be suitable. ${ }^{15}$ The Table (page 37) illustrates some of these scenarios.

References

1. Citrome L. Evidence-based medicine: it's not just about the evidence. Int J Clin Pract. 2011;65(6):634-635.

2. Sackett DL, Rosenberg WM, Gray JA, et al. Evidence based medicine: what it is and what it isn't. BMJ. 1996;312(7023):71

3. Citrome L. Think Bayesian, think smarter! Int J Clin Pract. 2019;73(4):e13351. doi.org/10.1111/ijcp.13351

4. Sackett DL. Evidence-based medicine. Semin Perinatol. 1997;21(1):3-5

5. Cohen AM, Stavri PZ, Hersh WR. A categorization and analysis of the criticisms of evidence-based medicine. Int J Med Inform. 2004;73(1):35-43.

6. Dutton DB. Worse than the disease: pitfalls of medical progress. Cambridge University Press; 1988.

7. Maggio LA. Educating physicians in evidence based medicine: current practices and curricular strategies. Perspect Med Educ. 2016;5(6):358-361.

8. Citrome L, Ketter TA. Teaching the philosophy and tools of evidence-based medicine: misunderstandings and solutions. Int J Clin Pract. 2009;63(3):353-359.

9. Accreditation Council for Graduate Medical Education. ACGME Common Program Requirements (Residency). Revised February 3, 2020. Accessed March 30, 2021. https: / / www.acgme.org / Portals / 0 / PFAssets / ProgramRequirements/CPRResidency2020.pdf

\section{Bottom Line}

Evidence-based medicine was initially conceptualized as a clinician-friendly approach to help provide high-quality individual patient care. It was not intended to dictate choice based on a single factor, and was not intended to replace clinical judgment. 


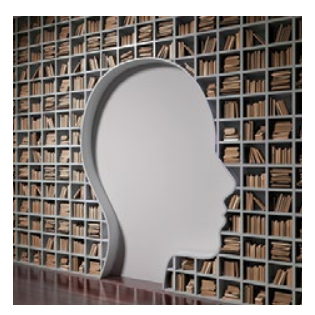

Evidence-based medicine
Evidence-based medicine continued from page 38

10. Citrome L,EllisonJM.Show metheevidence! Understanding the philosophy of evidence-based medicine and interpreting clinical trials. In: Glick ID, Macaluso M (Chair, Co-chair). ASCP model psychopharmacology curriculum for training directors and teachers of psychopharmacology in psychiatric residency programs, 10 th ed. American Society of Clinical Psychopharmacology; 2019.

11. Citrome L. Interpreting and applying the CATIE results: with CATIE, context is key, when sorting out Phases 1, 1A, 1B, 2E, and 2T. Psychiatry (Edgmont). 2007;4(10):23-29.

12. Citrome L, Stroup TS. Schizophrenia, clinical antipsychotic trials of intervention effectiveness (CATIE) and number needed to treat: how can CATIE inform clinicians? Int
J Clin Pract. 2006;60(8):933-940. doi: 10.1111/j.17421241.2006.01044.x

13. Citrome L. Dissecting clinical trials with 'number needed to treat'. Current Psychiatry. 2007;6(3):66-71.

14. Goldberg JF, Freeman MP, Balon R, et al. The American Society of Clinical Psychopharmacology survey of psychopharmacologists' practice patterns for the treatment of mood disorders. Depress Anxiety. 2015;32(8):605-613.

15. Citrome L. Food and Drug Administration-approved treatments for acute bipolar depression: what we have and what we need. J Clin Psychopharmacol. 2020; 40(4):334-338. 